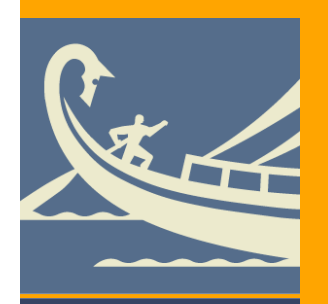

ITHAKA S+R

\section{In Pursuit of \\ Excellence and}

Inclusion:

Managing Change at Arizona State University

Kevin M. Guthrie

Christine Mulhern

Martin A. Kurzweil 


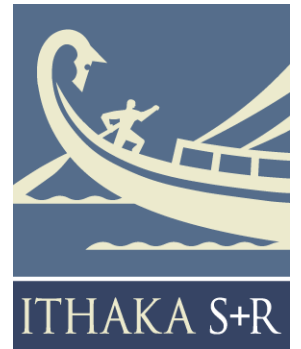

Ithaka $\mathrm{S}+\mathrm{R}$ is a strategic consulting and research service provided by ITHAKA, a not-for-profit organization dedicated to helping the academic community use digital technologies to preserve the scholarly record and to advance research and teaching in sustainable ways. Ithaka $\mathrm{S}+\mathrm{R}$ focuses on the transformation of scholarship and teaching in an online environment, with the goal of identifying the critical issues facing our community and acting as a catalyst for change. JSTOR, a research and learning platform, and Portico, a digital preservation service, are also part of ITHAKA.
Copyright 2015 ITHAKA. This work is licensed under a Creative Commons Attribution-NonCommercial 4.0 International License. To view a copy of the license, please see http://creativecommons.org/licenses/by-nc/4.0/.

ITHAKA is interested in disseminating this brief as widely as possible. Please contact us with any questions about using the report: research@ithaka.org. 


\section{Contents}

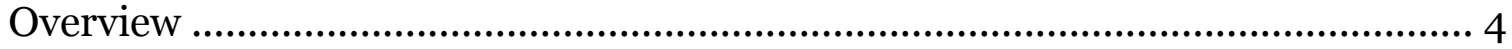

Vision, Targets, and Results ........................................................................... 6

Managing Change …..................................................................................10

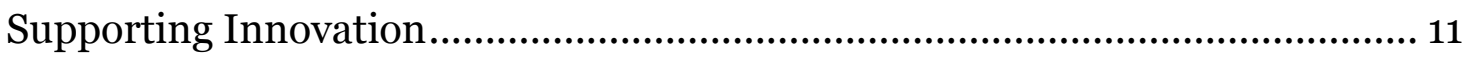

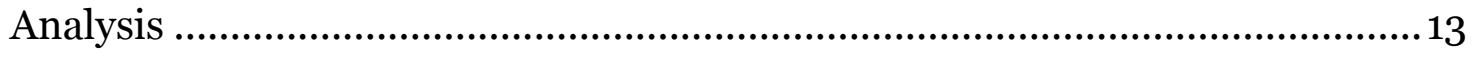

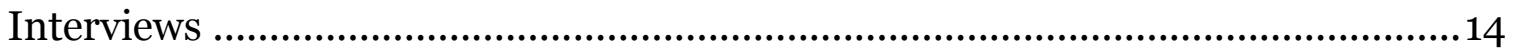

President and Provosts ............................................................................15

Michael Crow, President ...................................................................................15

Robert E. Page Jr, University Provost .........................................................16

Elizabeth D. Capaldi Phillips, Provost Emerita, University Professor, Professor of Psychology................................................................................19

Deans and Department Chairs …................................................................. 22

Richard Fabes, Director and Professor, The Sanford School of Social and Family Dynamics ............................................................................................ 22

Christopher Callahan, Vice Provost and Dean, Cronkite School of Journalism \& Mass Communication ................................................................................... 24

Mark Lussier, Department Chair of English, former President of the Faculty

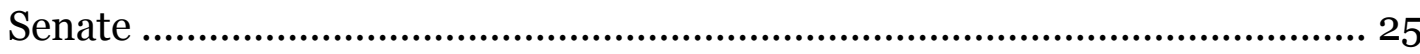

Teri Pipe, Dean, College of Nursing and Health Innovation.......................... 28

Philip Regier, Executive Vice Provost and Dean, ASU Online ..........................31

Keith Crnic, Department Chair for Psychology .............................................. 32

Mari Koerner, Dean, Mary Lou Fulton Teachers College................................. 33

Ronald Askin, Director, School of Computing, Information and Decision

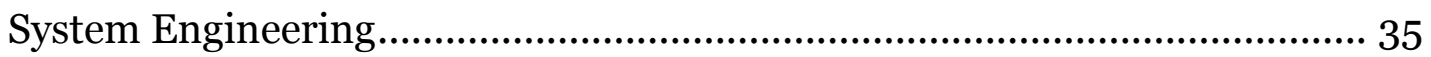

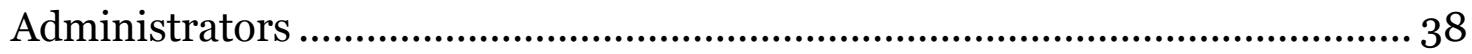


Morgan Olsen, Executive Vice President, Treasurer \& Chief Financial Officer

Arthur Blakemore, Senior Vice Provost, former Chair of Economics ............ 40

Sheila Ainlay, Executive Vice Provost for Planning and Budget ......................41

Gordon Wishon, Chief Information Officer, and Charles J. Kazliek, Vice

Provost for Technology ............................................................................... 43

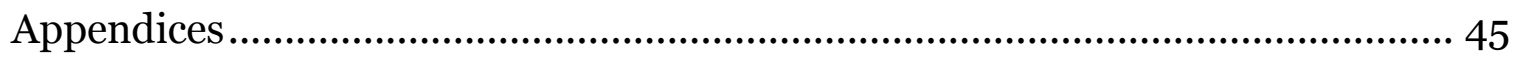

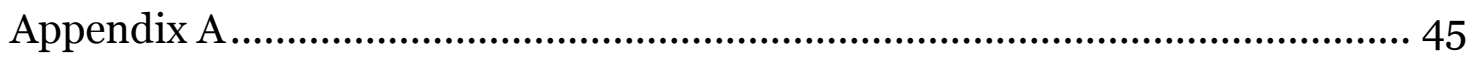

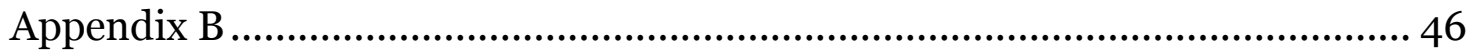




\section{Overview}

"The New American University." To the outsider, or to the leader of another higher education institution, it may sound like a brash and arrogant boast. On the inside, for a person associated with Arizona State University (ASU), it can be an aspirational expression of pride and the opportunity to take a leadership role in U.S. higher education. ASU and its president, Michael Crow, seem to conjure up strong reactions from observers and competitors, both positive and critical. For example, Newsweek says ASU is pursuing "one of the most radical redesigns in higher learning." ${ }^{1}$ In awarding him one of its 2013 Academic Leadership Awards, the Carnegie Corporation of New York noted that Crow is "nationally known for his commitment to innovation and to reinventing the research university model to emphasize access and excellence."2 On the other hand, critics have argued that the progress some applaud is not real, that it is nothing more than self-promotional sales and marketing. ${ }^{3}$ At base, ASU's experience under Crow's leadership poses two crucial questions: Is it possible for a large public university with a $\$ 2$ billion budget to change, innovate, and embrace a new direction? 4 And if so, what does it take to make that happen?

To begin to answer these questions, we traveled to Tempe, Arizona to conduct three days of interviews with senior administrators, deans, and faculty at ASU. We also consulted strategic documents and presentations provided to us by senior administrators for data related to institutional performance. Our interviews followed roughly the template used for our study of technology-enhanced education at public universities in the Public Flagship Network,$^{5}$ since it would offer us a basis for comparison. This research was not intended to provide a definitive answer to whether Arizona State is succeeding in serving as the model of a New American University; rather, it gathers evidence about whether things really are changing at ASU and whether senior leaders support those changes. To be as transparent as possible-and to encourage readers to evaluate the extent of change at ASU for themselves-we have reproduced our interview notes in this report.

\footnotetext{
${ }^{1}$ Stephan Theil, "Reinventing the Global University," Newsweek, August 8, 2008, http://www.newsweek.com/reinventing-global-university-87861.

${ }^{2}$ See the Carnegie Corporation of New York's press release dated December 9, 2013, http://carnegie.org/news/pressreleases/story/view/carnegie-corporation-of-new-york-honors-higher-education-innovators-with-2013-academicleadership-aw/.

3 See, for example, Jack Stripling, “Arizona State Has Problems, Just How Its President Likes It,” U.S.A. Today, July 16, 2010, http://usatoday30.usatoday.com/news/education/2010-07-16-ihe-arizona-state N.htm.

4 See 2015 All Funds Budget, https://cfo.asu.edu/budget-all-funds-budget.

5 See Deanna Marcum, Christine Mulhern, and Clara Samayoa, "Technology-Enhanced Education at Public Flagship Universities: Opportunities and Challenges," Ithaka $S+R$, December 11, 2014, http://sr.ithaka.org/researchpublications/technology-enhanced-education-public-flagship-universities.
} 
The data on institutional performance indicate that ASU is growing and becoming more productive on a variety of measures, and is making progress on becoming a more inclusive institution. Our interviews with leadership demonstrate strongly that the organizational culture has changed dramatically. The vision of the institution has been clearly communicated, is well understood, and has been embraced by the senior leadership. There is a shared sense of urgency and enthusiasm for innovation, in general, as well as the specific changes introduced by Crow. Those leaders also report that these views are widely held across the university and that the commitment to change has been institutionalized. Several people independently cited the same figure-80\%-as an estimate of the percentage of faculty who have embraced the new approach. Several also indicated that even if President Crow were to leave tomorrow, the university would continue on its current trajectory. In our judgment, the university is moving in a new direction, a direction focused on maintaining or improving educational and research quality while educating an ever-increasing number of students. 


\section{Vision, Targets, and Results}

It starts with the vision. ASU has established a straightforward vision to guide the activities of the institution and has stuck to those basic guiding principles for over a decade. The vision is as follows:

To establish ASU as the model for the New American University, measured not by who we exclude, but rather by who we include and how they succeed; pursuing research and discovery that benefits the public good; assuming major responsibility for the economic, social and cultural vitality and health and wellbeing of the community.

Some of the principles attached to the vision are that ASU will advance the fundamental principle of accessibility to all students qualified to study at a research university, and in ways that match the State of Arizona's socioeconomic diversity; that it will enhance quality while reducing the cost of a degree; and that it will enhance measured student development and individual student learning to national leadership levels.

During our interviews, time and again, administrators and faculty expressed that it was the clear and compelling vision that attracted them to the institution and continues to motivate them. That is not to argue that implementing the change has been either easy or swift. There was considerable initial resistance to the changes early in President Crow's tenure. People we interviewed indicated that it took several years to overcome that resistance. The vision played an important role in that transformation. While one can argue that it is difficult to increase quality and scale simultaneously, or that it is more difficult to improve graduation rates with a more inclusive admissions policy, it is impossible to argue that doing so would not be a good thing for society. For those faculty and others who may be resistant to change, it is a hard argument to make that this is a bad direction for a public university. This vision has served to align the institution as well as to convey a sense that ASU is pursuing something special.

\section{Time and again, [ASU] administrators and faculty expressed that it was the clear and compelling vision that attracted them to the institution and continues to motivate them.}

A clear and stable vision also facilitated the selection and cultivated the support of key leaders across the institution. Several people we interviewed noted that deans and other 
senior administrators who did not support the new direction were encouraged to leave and were replaced with people who were enthusiastic about the new direction. Further, once faculty realized that the new direction was indeed going to be pursued for the foreseeable future, those who did not want to be a part of it either joined in or left. This process has left the institution with deans and leading faculty who embrace the new direction and have been empowered to pursue it. There is an entrepreneurial spirit to how they talk about their work.

There's an old saying that you get what you measure. ASU has identified six targets as part of its strategic plan that is reported to the State Board of Regents annually. These targets are communicated throughout the university and are used to help guide resource allocation during the budgeting process. The targets for 2020 are: 25,000 total degrees awarded; 90\% first-time, full-time freshman retention rate; 75\% 6-year graduation rate; in-person enrollment of 85,000; ASU Online enrollment of 20,000; and \$700 million in research expenditures. Progress toward these targets is shown in the table below:

\begin{tabular}{lcccccc}
\hline Goals (Target in 2020) & FY 2009 & FY 2013 & FY 2014 & $\begin{array}{l}\text { FY 2014 } \\
\text { (proj.) }\end{array}$ & $\begin{array}{l}\text { FY 2017 } \\
\text { (proj.) }\end{array}$ & $\begin{array}{l}\text { FY 2020 } \\
\text { (proj.) }\end{array}$ \\
\hline Total degrees awarded (25,000) & 15,610 & 18,916 & & 18,155 & 20,941 & 24,352 \\
\hline Freshman retention rate (90\%) & $79.5 \%$ & $80.0 \%$ & $83.8 \%$ & & $87.5 \%$ & $89.0 \%$ \\
\hline 6-year graduation rate (75\%) & $55.8 \%$ & $56.8 \%$ & $58.6 \%$ & & $66.0 \%$ & $68.5 \%$ \\
\hline In-person enrollment (85,000) & 66,088 & 65,934 & 66,812 & & 78,217 & 80,915 \\
\hline ASU Online enrollment (20,000) & 994 & 7,444 & 9,959 & & 15,363 & 20,705 \\
\hline Research expenditures (\$700m) & $\$ 281.6 \mathrm{~m}$ & $\$ 405.2 \mathrm{~m}$ & & $\$ 411.0 \mathrm{~m}$ & $\$ 520.6 \mathrm{~m}$ & $\$ 700.0 \mathrm{~m}$ \\
\hline
\end{tabular}

ASU has made steady progress toward targets on each of these performance indicators. In addition, although it is not one of the formal targets, the 4-year graduation rate has also improved markedly, from 31.9\% to 45.1\% between FY 2009 and FY 2014. Impressively, ASU has achieved these gains without substantial change in the demographics or academic preparation of its student population. In fact, during this 
period the percent of undergraduates with Pell grants increased and the percent of minority students increased. ${ }^{6}$

These targets play a number of important roles in the transformation underway at ASU. At a practical level, they offer a simple and transparent way to measure progress and provide feedback to everyone at every level of the institution, from the board of regents to staff, about progress being made. Symbolically, they communicate very simply to everyone what is most important at the institution. All universities have complex multifaceted missions with a diverse range of stakeholders. To have a straightforward "scorecard" offers a powerful guiding force. Furthermore, ASU has made progress on these metrics over the last several years. This not only reinforces the value of the mission, but the successful progress provides inspiration and motivation to the faculty and staff of the institution.

\section{All universities have complex multi-faceted missions with a diverse range of stakeholders. To have a straightforward "scorecard" offers a powerful guiding force.}

In addition to the straightforward vision and the key metrics, senior leadership have also identified a set of four goal areas and eight design aspirations that provide more details about the boundaries that define how the institution should pursue the vision.7 For example, one could argue that the graduation rate could be inflated by giving passing grades to students that do not deserve them. Obviously, that would not be a beneficial way to make progress toward the target. Accordingly, the goal area to "demonstrate American leadership in academic excellence and accessibility" makes clear that standards of academic quality must remain high as the institution pursues inclusiveness. To ensure that the targets are pursued across the institution, and that strong units do not hide the weakness of other units, a second goal area is that ASU should "have national standing in academic quality and impact of colleges and schools in every field." The third goal area is to "establish ASU as a global center for interdisciplinary research, discovery

\footnotetext{
${ }^{6}$ The percent of undergraduates that are white decreased from 64\% in Fy2010 to 57\% in FY2014. The percent of first-time full-time degree-seeking undergraduates who received a Pell grant increased from 21\% in FY2009 to 29\% in FY2013. The admissions rate bounced around between FY2008 (92\%) and FY2O13 (89\%) with the low point being 82\% in FY2009. The $25^{\text {th }}$ and $75^{\text {th }}$ percentile of SAT scores increased by only 30 points for the math section and 20 points for the verbal section. See IPEDS Data Center, http://nces.ed.gov/ipeds/datacenter.

7 See appendix A for the list of ASU design aspirations.
} 
and development by 2020." Here, the key distinctive aspect of the principle is interdisciplinarity, which according to our interviews is a strategy for pursuing both exciting new research as well as cost-savings. And the final goal area is to "enhance ASU's local impact and social embeddedness." This goal is perhaps the hardest of the four areas to measure, but for obvious reasons is the one where progress is felt most directly by the State and local community.

These goals set a broad self-driven direction for the institution. At the same time, ASU recognizes that it operates within a system of rankings and competition, and so it also compares itself to its peers. One area of focus is financial measures of performance and productivity, both on the revenue and expense side. In its February 2014 report to the Arizona Board of Regents, ASU highlighted several of these comparison points. Using IPEDS data, ASU determined that it charges students and the state less per degree than its peers: its FY2O12 revenue from net tuition, fees, and state appropriations per degree awarded was $\$ 55,604$, significantly lower than the median for peer public universities of $\$ 77,706$. On the expense side, ASU measures staff productivity by calculating the total number of employees per 100 FTE students. ASU has consistently had a ratio of approximately 10 staff per 100 FTE students; the median for peer institutions is approximately twice that figure. Similarly, the number of faculty per 100 students has also been half the median level for peer institutions at approximately 4 faculty per 100 students. ${ }^{8}$ According to the National Science Foundation Higher Education Research and Development Survey, in FY2012, ASU's non-medical research expenditures ranked $32^{\text {nd }}$ overall (Table 33); its research expenditures ranked $8^{\text {th }}$ in social sciences and $13^{\text {th }}$ in nonscience and engineering fields (Table 21).

8 “Strategic Enterprise Report Framework," Arizona Board of Regents Meeting, February 7, 2014, pages 23-31. 


\section{Managing Change}

One of our objectives in conducting interviews with the senior staff and faculty was to determine whether the changes ASU has claimed have been institutionalized. Although we interviewed a very small and non-representative sample of people, we observed consistent agreement about the direction of the university and what it would take to go there. This alignment is quite different from what we observed in the interviews that we conducted as part of the study of universities in the Public Flagship Network. In this section we offer some informed speculation on why these conversations seem different and how change is being managed.

1. A compelling and incontrovertible mission has been articulated. Everyone has heard it and understands it. Although it encompasses objectives that are hard to achieve and it challenges people's current ways of working, the vision is expressed in a way that is aligned with what one might expect for a public university. It is difficult for anyone to argue that it represents a bad direction.

2. In addition to the broad vision, a simple and straightforward set of metrics have been identified that are monitored at every level of the institution from the board of regents down that serves to focus resources and activity on the most important things.

3. A slightly more discursive set of objectives set boundaries for what is intended. These goals provide general direction to leadership and staff and empower them to pursue the objectives in ways that work most effectively for them.

4. There is strong receptivity to risk-taking and empowerment. The language of the institution and its leadership emphasizes innovation. There is a sense of urgency and a sense that everything needs to keep moving. At the same time there is acceptance that some failures are a natural outcome of taking such an approach.

5. There is a belief not only that change is encouraged, but also that change actually can happen. Several of our interviewees said that if you have a good idea, at ASU you can get resources and can get it done. Only one interviewee said that standard university bureaucracy often got in the way. It would be a point worth following up on in further research.

6. The mission, the message, and the approach have been stable for a decade. The persistence has been an important contributor to the success in changing the culture. It was said a number of times that those who were reluctant or resistant have either left or have come on board. This takes time. 


\section{Supporting Innovation}

In addition to creating an environment and culture that rewards innovation, ASU has also made substantial investments in staff and infrastructure to support new approaches. The most substantial of these is ASU Online. ASU Online is viewed as a mechanism for increasing enrollments dramatically while managing costs-especially capital costs. ASU Online also offers services to support online courses provided to residential students that come to campus. The online courses taken by residential students are called iCourses, and have been the mechanism for importing lessons learned from ASU Online to courses for students on campus. More and more faculty every year are experimenting with online and hybrid instruction and so there has been substantial growth in the availability of iCourses on campus. For the most part, the focus in creating these courses has been on improving learning outcomes and enriching the student learning experience rather than on reducing costs. ASU has not yet started to account for costs on a course-by-course basis nor have they compared the costs of online versus face-to-face instruction to determine which approaches are more cost effective.

The fact that ASU Online was established as a separate service with its own leadership and ambitious goals enabled it-perhaps even required it-to pursue new approaches, including partnerships with outside enterprises, companies and partners. ASU Online lists approximately 100 different services that operate as "third-party tools" used by faculty and students in ASU Online courses. These services are broken down into six different areas: Identity Management; Personalized Learning; Assessment; Collaboration; Interaction; and Content. More than 50 of these services require direct interaction with a vendor representative and are therefore not just services used over the web but involve deeper collaboration.

ASU's interdisciplinary focus was cited as a source of both substantive and fiscal innovation. When ASU, like many other public universities, faced a substantial decline in state appropriations following the 2008 financial crisis (over \$196 million, from \$496.3 million in FY 2008 to $\$ 300.0$ million in FY 2012), the administration committed to preserving academic programs while reducing administrative costs. This goal was accomplished largely by accelerating the effort to consolidate departments into interdisciplinary units. These structural changes were generally supported by the faculty, who in some cases proposed the mergers. The new structures have encouraged research collaboration across fields and have also facilitated efficiencies in instruction (for example, by breaking down bureaucratic barriers to dissertation advising).

Another key area of innovation highlighted by our interviews has been the development of what is called e-Advisor. This service combines about 30 different applications and programs to provide analytics and dashboards that provide ASU administrators with a 
more complete picture of every student and his or her progress. This information enables ASU to intervene to provide intelligent assistance to help students before they veer too far off track. Everyone points to this system and the information it offers as a key factor in helping them to improve freshmen retention and graduation rates. For a summary of the e-Advisor service, please see Appendix B. 


\section{Analysis}

ASU is in the middle of a major change in culture, focused on creating a more innovative institution that can teach more students at lower costs while maintaining quality in both teaching and research. There is considerable evidence that the culture has changed and that the institution is embarked on a new strategic direction. There is also evidence that ASU is making progress on key self-identified measures of success. Enrollment is up. Freshmen retention is up. Six-year graduation rates are up. Research expenditures continue to increase. Various measures of productivity are improving and compare very favorably against peer institutions. It is a compelling story. It would be valuable to gather more evidence than was possible in this effort about how ASU ensures that it is maintaining quality as it increases numbers of graduates, decreases the faculty: student ratios, or as it attracts more research funding. That said, it is evident that ASU embraces both the ideals and the practical realities of using today's technologies and opportunities made possible by network communications to meet the challenges ahead.

At the same time, the environment around colleges and universities is constantly evolving. ASU has the advantage of being an early mover among research universities providing online learning at scale. This has enabled ASU to increase enrollment and revenue relatively quickly. ASU's leaders will surely be tempted to use the new revenue from this growth solely to subsidize and support the traditional activities of a research university. To some degree that is both necessary and wise, since any research university needs enthusiastic support of its faculty to be successful. At the same time, it will be very important to continuously re-invest in the new technologies and the services they make possible, including focusing on ways to teach more students more effectively at lower costs. Surely the marketplace to attract online students will become more competitive in the years ahead. ASU will need to use its early mover advantage to stay ahead not only in terms of user facing tools and content, but also in terms of educational productivity. There is a real risk that early success might cause ASU to take a conservative approach that starves the very innovation that has invigorated the institution and that is necessary for its continued success.

\section{ASU is in the middle of a major change in culture, focused on creating a more innovative institution that can teach more students at lower costs while maintaining quality in both teaching and research.}




\section{Interviews}

In the spirit of transparency, we have supplemented the Overview above with virtually unfiltered notes from the interviews that are our main sources. Guthrie and Mulhern traveled to Tempe on August 25-27, 2014 and conducted all but one of the interviews. (They conducted the interview with Elizabeth Phillips by phone on November 17, 2014.) The descriptions below are not transcripts but rather Guthrie and Mulhern's notes. We have organized and lightly edited them for coherence, and the interview subjects have reviewed the notes and in some cases suggested edits to clarify their meaning.

We have arranged the interviews by position within ASU, starting with the president and the current and former provost, moving on to deans and department chairs, and ending with other administrators. In the Overview, we explain the summary points that were most salient to us. The interviews include much more and richer information about ASU's experience under Michael Crow. We encourage readers to review these interviews and judge for themselves the degree and institutionalization of change at ASU. 


\section{President and Provosts}

\section{Michael Crow, President}

One of the areas on which President Crow has focused much attention is to express the purpose of the institution very clearly and succinctly. The original mission of the land grant institutions was to admit a quarter of the population to research grade universities, but more recently some of these institutions have become more exclusive. ASU is trying to pursue the original objective. 9 While doing so, those at ASU also work to match the diversity of the student body at ASU to the Arizona population.

In addition to not wanting to limit access to the institution, ASU is empowering the faculty to become student centered. Administrators tell faculty not to come to ASU if they do not want to teach. The Provost is responsible for measurement of student outcomes. ASU is in the top 20 among research universities for all measured learning outcomes and the faculty objective is to give all students the same chance of success. ASU does not want to be what President Crow calls a "weed out" school, a place where the objective is to get rid of students during the freshmen year. His team has made freshmen retention a top priority goal of the university. They chose their retention target-90\%-because it is the target pursued by the best selective universities that admit only $10 \%$ of their applicants. President Crow wants to meet that standard while admitting $25 \%$ of the Arizona population.

President Crow has pursued these ambitious objectives by articulating a clear mission, setting up an environment that embraces change, and empowering the faculty to pursue it. He is working to replace a culture of tradition with one of innovation. "You don't have to innovate," he said, "but you can't prevent someone else from innovating." In doing so, he has emphasized the importance of data and evidence driven innovation with a relatively high appetite for taking risks.

He feels that it is important to lead with important initiatives that are consistent with this ethos. The recent partnership with Starbucks is such an initiative, although he does not regard it as a big risk in part because he believes the mission and interests of Starbucks and ASU are well aligned. The core of the Starbucks partnership is to help Starbucks employees complete their undergraduate educations. It is not surprising that a high percentage of Starbuck's employees have taken some college courses but have not completed a bachelor's degree. President Crow believes that through its experience with ASU Online, ASU is well positioned to provide support for the Starbucks employees to

9 Although ASU is not in fact a land grant university, it views its mission and resources as similar to one. 
enable them to complete their degrees. The early indications are positive, as 4,000 Starbucks employees have applied and 1,00o enrolled in Fall 2014. ASU has a 91\% retention rate in its online programs and aims to duplicate this success in the Starbucks partnership in a way that can demonstrate that degree completion is possible for this population.

We closed our interview with a question about what President Crow would do with a $\$ 50$ million grant. He said that he would continue to build opportunities for faculty to leverage collaboration, especially focusing on interdisciplinary work. He would also invest in initiatives and provide resources to every faculty member that further empower those faculty to express their creativity to a broader audience than just their face-to-face students. He would also invest further in using data analytics aimed at lowering costs. Finally, he would support adaptive learning technologies, especially for general education courses, so that students could move through programs more quickly.

\section{Robert E. Page Jr, University Provost}

Provost Page is an esteemed professor and researcher in entomology, who came to ASU from the University of California Davis in 2004. He was attracted to the university because of Michael Crow's vision and because he thought he could do something at ASU to make a difference-for the students and for the institution. He had a very limited ability to change the direction of the ship at UC Davis.

He was hired as the founding director of the School of Life Sciences. He held that position for 7 years, and in 2011 he was named the Dean of the College of Liberal Arts and Sciences. In 2013 he was named University Provost. According to Michael Crow, Provost Page just kept succeeding so Crow had to keep giving him more responsibility.

Provost Page described ASU Online and how it has been the entity through which ASU makes online programs available. The design principles at the outset were that it would be self-contained so that all degree programs will be built inside it. It was built in this way to help deal with the faculty prejudices about online learning.

There was a lot of initial resistance to ASU Online. Phil Regier was approached to build the initial online degree programs and was named the Dean of ASU Online. These were very centrally contained so that Dean Regier could control the initiative. He was empowered with considerable leeway to build the program; he could decide which degree programs to offer and work with the department chairs directly. (He often bypassed deans because they were resistant.) He was given the latitude to return funds directly to departments to provide motivation for departments to work with ASU Online. 
His plan included providing assistance to develop the courses and to market degree programs.

Within this silo Dean Regier's team built degree programs that were being created by faculty at ASU. Control of the content and the curriculum stayed with the academic departments. In this way ASU Online had the freedom to grow the new programs while the faculty still retained control over the academic side of the courses. As the online courses grew in popularity externally, there was increasing pressure to embrace digital technologies to make courses for their immersion students better. Dean Regier's team developed different mechanisms for using the web-based materials and experimented with different platforms. In this way the experience externally was feeding the knowledge internally. There was also a push (especially by Provost Page as the College of Liberal Arts and Sciences dean) to enhance the experience, improve outcomes and reduce the need for huge classrooms. There was an emphasis on flipping the classroom and teaching hybrid courses. The ASU Online experience helped to motivate experimentation and innovation on campus as well. Courses taught to immersion students using online technologies are called iCourses.

At the time that Page became Dean of the College of Liberal Arts and Sciences (CLAS), there was a lot of negative push back to online learning. The other deans were very opposed to it and they were not trying to encourage the department chairs to get the faculty online. As mentioned above, Dean Regier and his team were working (or trying to work) directly with faculty and departments to try to get them involved in ASU Online. When Page started as Dean, CLAS basically was not playing along and they were the biggest college. Page went to the associate dean for courses to ask which courses would be best suited to put online and which majors would be best suited for an online program. He built a team and sent them out to bring the faculty in and help them build the online courses. Then the faculty started understanding and engaging with online learning and it snowballed very quickly.

When he left to be provost he had to slow the process down. Forty percent of student credit hours across the university were being taught online and he was circumspect. Because it had happened so fast and he was not sure what the courses were delivering, he is putting in place standards and a process to get approval for a new online course. Currently, online courses do not go to the faculty senate if they are based on a course that is already established as a face-to-face course. Because most of the online degrees are using courses already built for face-to-face majors, there is no faculty senate approval. The new approval process is meant to evaluate the course and degree format.

As online learning grew throughout the university, ASU Online started to lose staff to other internal initiatives. The colleges were hiring people out of ASU Online because, as 
they grew, they felt like they needed the expertise locally. It became clear that with the growth in online learning for both immersion students and external students, the segregation of ASU Online from campus based instruction was beginning to be problematic. Provost Page has developed a more integrated approach called Ed+. Ed+ helps with improving cross-campus communication, teaching faculty to engage with digital teaching, and creating course builds. Ed+ will be an umbrella of services related to online instruction, with ASU Online as one component-the component focused on managing the online degree programs on behalf of the departments. But Ed+ will manage relationships with technology partners and service providers, and generally build the infrastructure and provide the staff to support continuous innovation in online and hybrid courses.

ASU (with Knewton and Pearson) has built adaptive learning courses in early-college math. These courses are a critically important foundation for STEM courses and majors. A lot of students were coming in without the math qualifications and skills that they need. These courses have been successful, and ASU is now building additional adaptive learning gateway courses for general studies in the sciences. These include psychology, biology, physics, economics and chemistry. These are the large enrollment courses and they are not as successful as they could and should be.

ASU is also testing the development of technology-enabled interdisciplinary general studies courses that are set up around a theme. "Habitable Worlds" is the leading example of such an integrated course and it has been very successful and popular. Other thematic general studies courses are in development.

In contrast to when Provost Page first arrived at ASU, the faculty are very actively engaged in online learning. There are whole departments flipping their courses and ASU is building classrooms to accommodate these types of courses. There is a focus on problem-based learning rather than lectures. There has been a sea of change in how Michael Crow's vision has been embraced. In 2004 the faculty were still in shell shock. The faculty then did not have a sense of pride in ASU and they struggled to do their research. Those outside the university thought more highly of ASU than those in the institution. Over time, President Crow's persistent and constant message and the points of success he cites have made the faculty proud of ASU. The faculty are taking ownership of this change and these successes, especially over the past 2-3 years. The whole conversation changed and ASU hired a lot of people who came here because of President Crow's vision and because of ASU's success and dynamic environment. Provost Page estimated that $80 \%$ of the faculty have embraced the vision. 
According to Provost Page, ASU is a place where people can actually build programs. President Crow's attitude is that if you have a good idea we'll make it happen. You can get the resources and the buy-in.

\section{Elizabeth D. Capaldi Phillips, Provost Emerita, University Professor, Professor of Psychology}

Elizabeth Phillips began as Provost at ASU in 2006 after previously serving as provost at the University of Florida and SUNY-Buffalo as well as the Vice Chancellor of SUNY. This was four years into President Crow's tenure (he started in 2002). Although considerable changes had already been implemented by the time she arrived, there remained much to accomplish related to Michael Crow's vision for change at the university. She saw an opportunity for technology to help with significant aspects of the necessary transformation, as she has had a firm belief in the benefits of thoughtful uses of technology, especially as it is used to support student success. She helped develop the electronic advising system, Tracking, at Florida, and brought this to ASU, where it became eAdvisor.

Dr. Phillips' primary role was to implement the vision that President Crow set forward. She determined what they could do and how they could do it while still achieving the aims that President Crow set. Her own approach to leadership at ASU was not to be directive or hierarchical, but rather to appeal to the fundamental mission of supporting student success and by looking for and pursuing those faculty who were prepared and eager to try new things.

In the early vision for ASU in developing the New American University, a key component was to treat each student as an individual. Dr. Phillips helped to deepen that particular goal to focus on student success while maintaining a commitment to personalization. In fact, the focus on the individual helped spark some of the initial technology experiments in teaching and learning, especially a partnership with Knewton to develop a platform for adaptive learning courses. Interactive technology enabled faculty and administrators to see how each student was performing, what assistance he or she needed and how instructors could better target their teaching. This enabled instructors to reach students more effectively than in a traditional large lecture course. Adaptive technology in math also saved resources, reducing the number of sections and therefore the number of TAs and physical facilities.

Dr. Phillips' relationship with the faculty senate (and more specifically the executive committee) was extremely important in furthering the changes the institution was pursuing. There were zero secrets; she told them everything. Members of the faculty 
senate executive committee learned that they could trust her and nothing ever happened about which they did not know. It was very valuable to her to have their trust.

The large decline in state appropriations induced by the 2008 financial crisis was a huge challenge, and forced ASU to make changes more quickly than would normally be possible. As its primary goal the administration decided to reduce costs without affecting academic programs, and communicated that goal to the entire university community. The administration therefore sought savings by reducing administrative staff, primarily at the college level; by consolidating administrative offices and staffing across multiple campuses; and by combining departments into interdisciplinary units. This restructuring helped to solidify ASU's commitment to interdisciplinarity. Certain things can now be done at ASU that cannot be pursued in a more "traditionally" structured institution because the departments are organized in that way. For example, an ASU faculty member can supervise a PhD candidate from a different department. These changes are challenging to implement and of course have their dissenters. Engaging the faculty in that process is essential. It is important to note that many of the ideas for mergers came from the departments themselves who were working alongside administration to find the expense reductions while protecting the academic positions.

Dr. Phillips saw online learning as one way to maintain emphasis on student success in a constrained budget environment, especially through adaptive and personalized learning approaches. There was never a faculty vote about the decision to increase the emphasis on online learning technologies. Rather, the ASU administration promoted a spirit of entrepreneurship and worked with those faculty and departments that wanted to engage in online learning. Dr. Phillips started by working with the many faculty who were already teaching online. She created a Provost group for excellence in teaching with technology. The early successes of working with those who wanted to go online motivated others to teach online and put degrees online. The administration also created positive incentives by distributing a portion of the revenue generated from online courses directly back to the departments that offered the courses. By taking this approach, no one was forced to teach online or to put a degree online. Faculty made their own choices.

One of the primary focuses of ASU Online was to reach students who are not able to access the traditional, residential university experience. This focus had to be clearly defined because many faculty were already teaching courses that were hybrid or online but were intended for residential students. Thus ASU Online courses were designated for students who complete their entire degree online and do not attend classes on campus. Faculty could simultaneously teach the same online course to their traditional students and their ASU Online students (but in different sections). This was important because enrollments in ASU Online were initially small; for example, there were online sections 
with only four students. Because an additional online section had low marginal cost (and still produced some net revenue), ASU Online was able to test the efficacy of online-only degrees with a small number of students and refine the offering before scaling up. Even these small sections brought in some incremental revenue that could be used to improve the program and help with the budget challenges. Obviously this aspect increased as ASU Online grew.

Arizona's relatively few higher education regulations made it easier to implement online courses and degrees than it would have been in another state. ASU did not need approval from a regulatory agency or accreditors for courses or degrees that already existed in their face-to-face offerings. It only needed approval from the board for the fees associated with ASU Online. Overall, the board was very supportive of online learning, including adaptive technologies and eAdvisor.

Dr. Philips mentioned that some aspects of ASU's success have been determined by the characteristics of their state, so these changes may not be replicable elsewhere. One example is the aforementioned minimal regulation. Another is a cultural and political commitment to an egalitarian approach to things in Arizona. This broad emphasis on inclusion extends into the structure of higher education, as there is not the same kind of tiering among public universities that exists in most other states (for example, the difference between the University of California and California State University systems). Moreover, as the only public university in the Phoenix area, ASU saw both an opportunity and a need to grow to serve the local population, recognizing that in doing so it would have to meet the needs of a wider range of students. Commenting on aspects that may be more transferable, and not limited to the situation in Arizona, Dr. Phillips believes that the use of technology to support student success is universal; she also thinks that interdisciplinarity will spread. ASU's reputation for interdisciplinary work has attracted faculty who want to work across disciplinary lines.

Dr. Phillips believes the changes at ASU have been institutionalized and will persist if a new president were in place. There is momentum behind the changes; everyone who was hired believes in interdisciplinarity and most are supportive of inclusion; and the university is financially structured to support the changes. Practically all of the faculty have bought into this approach because, in her opinion, most faculty believe in the need for high quality teaching and student success. That is a major reason that they have chosen to make education their life's work. 


\section{Deans and Department Chairs}

\section{Richard Fabes, Director and Professor, The Sanford School of Social and Family Dynamics}

Professor Fabes is the founding director of the Sanford School. It was one of the first schools established as part of the new reorganization and has been very successful. The school has grown considerably during his tenure. The school generates close to 30,000 credits and only the English and math departments teach more students. Sanford is a leader in attracting research grants: expenditures exceeded \$7 million for the 2013-2014 academic year, which is more than most social science schools and departments at ASU. The school is a model for other schools because of its growing enrollments, increased grant income, and growing revenue from online learning. Sanford teaches more students online than any other school.

Sanford offers two completely online degrees and many of its face-to-face and undergraduate classes are offered as iCourses. The online courses generate considerable net revenue. Although Professor Fabes admitted that he does not have rigorous data to back it up, his impression is that the online courses offer as good an experience as the face-to-face courses. Both modes of delivery have the same objectives. He noted that just because a class is offered face-to-face does not mean that it is delivering a great student experience or outcomes. Some faculty are great at face-to-face instruction and some are not. The anecdotal stories on both sides tell him that online is comparable to face-toface. The complaints are equally balanced as well. He finds it particularly satisfying to receive emails from graduates who express great appreciation for the online experience who say that without that option they never would have been able to get a degree.

There is one set tuition for online students because there is no way to differentiate between in and out-of-state students. As a general university policy, the department/school receives $\$ 250$ for each student enrolled in an online course. In addition to paying for the direct costs of the instructors of the courses, revenue from online courses is used to support research projects, graduate students, and post-docs. He has hired four faculty/lecturers who teach exclusively online. These lecturers are fulltime and dedicated to the program (they are not adjuncts). They have career pathways and he works to ensure that the lecturers are appropriately compensated.

Overall, the School earns \$1.4 million (net) from online course enrollments. This is transformational, especially in comparison to the $6 \%$ in unrestricted funds they receive from the $\$ 7$ million dollars of grants and annual expenditures. There is a scarcity of 
unrestricted discretionary funding so the revenue from online courses is incredibly valuable.

For the first time they are going to offer a Master's degree in Family and Human Development totally online. Professor Fabes will be teaching the first class. They had about 120 applications; 95 students will be starting in the program during Fall 2014. Students can start any semester and he estimates 50 more will start in the spring. He anticipates that the Master's program will generate about $\$ 750,000$ over the next two years if they keep the enrollment about the same. There will be some special challenges for the Master's degree that they will have to address; for example, how to facilitate good group discussions. They have also decided not to require a thesis but instead to have a capstone project. Exams in the online course will have to be multiple choice.

ASU Online takes responsibility for all marketing for Sanford's online courses and degrees. They get the word out and generate student demand for the courses/programs. Consequently, when you look at the Sanford School's section of the ASU website, there is not much emphasis on online programs. It is just focused on the discipline, the activities of the school and the courses that are offered. ASU Online also provides instructional support to faculty when they are preparing their courses.

Professor Fabes said that Michael Crow's vision has been institutionalized pretty deeply and broadly in the institution, and he believes ASU is on a path that would continue even if President Crow were to leave. Included in this change are commitments to improve certain measures, such as tripling research grant expenditures, improving freshmen retention and graduation rates, pushing for master's degrees (which is different from five years ago), and maintaining enrollments. These figures are reported regularly to the office of institutional analysis.

One important challenge is that the environment is extremely dynamic and Professor Fabes worries about how changes might impact them. For example, it would be a problem if there were a change in the revenue passed through for online courses, not only because it would reduce income, but because it would make it difficult to hire faculty because you could not count on the recurring funding that is necessary to make long-term commitments.

Professor Fabes emphasized the importance of strong and principled leadership, both at his level and at the level of the university. Change will not happen fast enough if it comes only from the grassroots from faculty; faculty want decisions to be more democratic and made more slowly. Faculty are not engaged with the fiscal realities-for example, they do not have to worry about how to reduce costs-and also are not naturally incentivized to 
embrace and pursue change. The leaders need to make the big decisions with thoughtful faculty input.

Generally speaking, the Sanford School is a good example of a school that is thriving under the new leadership. The school has identified key measures of success that are consistent with the broader objectives of the university and is meeting them.

\section{Christopher Callahan, Vice Provost and Dean, Cronkite School of Journalism \& Mass Communication}

Dean Callahan arrived at The Cronkite School in 2005, one year after President Crow had made the school an independent unit. It is one of the smallest schools and has 40 full-time faculty. It is a professional school in a profession that is undergoing massive change because of technology and network communications. It therefore has to be flexible and dynamic. The school is changing the curriculum by the semester and is in a constant state of evolution. There is a new kind of course every semester. For example, there is a new course on "designing news products for your tablet." There will also be a new program in the spring focusing on audience engagement. Faculty are modifying the content based on how the field is evolving very quickly and radically. How they are teaching the content is changing, too, but in less radical ways.

Callahan was recruited to be the first dean of the school operating as an independent unit. Started in 1984, the Cronkite School was originally part of one of the ASU colleges. He has been changing the focus from typical news journalist education to highly immersive unique learning environments. His vision is for students to work with fulltime non-traditional faculty (often journalists) to integrate what they learn in coursework with experience in practical professional settings. He believes journalism education should be parallel to medical education, where you have to be engaged in the practice as you learn the theory. The Arizona public broadcasting station is now part of the school and offers a real professional environment that supports this type of education. The students do not run the show, as in a campus newspaper; instead, like in a hospital, you have serious and esteemed professionals delivering the product while the students participate, contribute and learn. This brings the university supervision to the experience of producing real journalism. And ultimately, the quality of the end product is evaluated by the public/consumers.

As far as pedagogy and online learning, they started creating hybrid courses in topical areas where it made the most sense, such as survey courses covering topics like the history of mass media. These were originally taught as hybrid courses but they are morphing into fully online. The school has been slower to use online for the specific skills-oriented courses that require a lot of one-on-one or small group interaction. 
The school created a new degree, a Bachelor of Arts in mass communication and media studies, through ASU Online. This is the first online undergraduate degree program in mass communications. In this degree program, every course is online and completely separate from other courses at Cronkite. The differentiation helps them avoid the problem of competing for students on campus because there is a completely new and different set of students from outside. Starting this degree program offered another benefit: some senior faculty who were not central to the new professionally oriented, immersive part of the curriculum were re-invigorated by the mass media online program. The principles taught in this BA program include the important, time-honored mass media curriculum, and so faculty comfortable teaching that content gravitated toward it, even though it involved teaching in a new way. This has been great in reengaging those faculty-they are now central and leading the online degree program. The program is off to a great start. The planners had originally projected 75 majors in the first year, and 125 majors in the second year. They are already up to 450 majors in the beginning of the second year.

ASU Online acts as support for all the online courses and the school pairs a faculty member with someone from ASU Online to develop each online course. This support includes marketing, platform set up, and instructional technologists who instruct faculty on how to teach on the platform. The faculty have strong support but complete independence in developing their content and approach.

The accrediting body for journalism schools is assessment focused. The assessments include an external portfolio review, the impact the school has on the community (e.g., ratings of the PBS programming) and how many people are reading the articles they produce. They also measure and evaluate job placement rates.

Dean Callahan believes that Michael Crow's changes have become institutionalized. There were challenges and natural resistance in the early years, but now the principles and vision are embedded in the institution's culture. He is excited that people from other institutions are now coming to him to hear about the way the school is achieving its goals, and the question for him is how to continue to lead. The things that most worry him are not related to the internal institution, but rather how to keep innovating at a rate fast enough to lead the changing environment around journalism, media and communications and the web.

\section{Mark Lussier, Department Chair of English, former President of the Faculty Senate}

Professor Lussier is beginning his second year as chair of the English Department. He was president-elect, president and past-president for the faculty senate at the Tempe 
campus and also served as the chair of the university academic council from 2009-2012. He has been a member of the English department since 1993 and saw the initial wave of hybrid and online courses.

Professor Lussier designed the content for one of ASU's first online courses in 2002. He was familiar with the work of Jerry McGann at UVA's Institute for Advanced Technologies in the Humanities and he wanted to experiment with similar principles. His online course had a hybrid dimension and a one-hour technology lab. Students made a quantum leap in that class; some students initially did not know how to use email. The course used a final exam based on Frankenstein that made full use of interactive and online media. The outcomes were great because the students who usually would have just sat there were actively engaged and excited. He has been an early advocate for the benefits of these new kinds of learning enabled by technology.

Key changes were required to support more widespread delivery of online courses. One of these was to shorten courses to 7.5 weeks in response to market forces. ASU also decided that it would be necessary to break courses for "immersion" students into two halves. (Immersion students are residentially enrolled students, as opposed to the ASU Online students.) One challenge has been maintaining an appropriate distinction between the iCourses (taken by immersion students) and the ASU Online courses. The ASU Online courses are less expensive than the iCourses and it is therefore important to maintain a difference. Sometimes the same faculty member is teaching the same course as an iCourse and an ASU Online course, and it can be hard to separate the two. One way this is managed is by placing immersion students and ASU Online students in different "sections." They have separate online course groups in which only their peers are included.

That said, there is a certain drift toward growth in ASU Online students. One of the reasons is that there are a large number of potential students who want to take courses without making a full-time commitment to school. Another is related to the financial incentives for ASU in delivering online courses. Departments receive $\$ 250$ in unrestricted funds per student in ASU Online courses. There is also the reality that senior leadership and the regents have identified online courses as an important way for ASU to meet the challenges of being inclusive in educating as many students as possible. Key performance measures are the number of online students, freshman retention and degree completion.

English has two online undergraduate degrees, one in Film \& Media Studies and one in English. They have an online MA in Film, Cinema and Pop Culture starting in the spring. English has a growing number of majors online and that will grow even more when they 
open the MA. Department enrollments are now climbing again and have rebounded from a previous decline.

The initial design of online courses is done by tenure-track faculty and the courses are often taught by tenure-track faculty as well. The tenure-track faculty are responsible for quality control. There are shells for each course and other faculty in the department can use them. These courses have to meet the same standards as traditional face-to-face classes for accreditation. There is a serious commitment to evaluating outcomes for the courses. They measure outcomes for online, hybrid and face-to-face. The outcomes evaluated vary from course to course and across disciplines: some look at grades (if it is a more subjective field), and others measure more quantitative outcomes. These data are reported to the office of institutional analysis. All courses are evaluated by students, too, and each department has an assessment person who ensures that courses targeted for analysis are analyzed.

There is a serious commitment to interdisciplinary work at ASU, both in teaching and research. For example, the English department offers a specific "Science and the Imagination" track through its online BA degree, which makes use of transdisciplinary entities like Center for Science and the Imagination (whose director has a $25 \%$ appointment with the English department). Quite a number of faculty in English have secured grants supporting interdisciplinary work and a few have even served as PIs or co-PIs for NSF and other grants. This kind of collaboration is happening all over the university. Environmental and medical humanities are two important examples of the transdisciplinary focus growing in intensity in the department. They are infusing elements of the English program in these and other programs. (ASU's English department generates more research grant expenditures than most English departments in the country and was first in this category for two of the last three years.)

The department is trying to determine how English can be more engaged globally and in the community. It is partnering with business, engineering, math and economics faculty to provide entry level international students with tools that allow them to be more successful. When ASU decided to pursue that project, it took the program from concept to initial implementation in just eight months. It will be fully operational in just 18 months. That program is a notable example of how people with ideas can quickly act upon them and receive the resources to make them happen at ASU.

One of the special qualities of ASU now is that if you have a good and creative idea, you can get things started. If the initial outcomes are good you can get resources to expand it. The university does not thwart innovation; it encourages it. So much change and flexibility can be intense but it is not unbearable and at times it is thrilling. Some worry that high velocity change is the end, not the means to an end, but Professor Lussier likes 
being in an environment where if you can think of a solution you can do it (and you are provided the resources).

It is difficult to argue with the success that the university has achieved and is achieving. There were initial challenges. The former president brought the university into a Research I category, which was fantastic, but when President Crow came, the speed of change accelerated. There was some early resistance but that has been overcome. For the most part, the faculty that did not want to be a part of it have either left or are now supporting the changes.

Reflecting on his time as a faculty senate leader, he said that the partnership between faculty and the administration (and President Crow) was an effective one. There is no doubt that there was strong top down leadership and a strong vision, but it was also evident that the President listened to the faculty, especially about important issues. He cited examples when President Crow shifted course to respond to important faculty input; for example, making adjustments to budget reductions in response to faculty concerns.

There is genuine excitement at ASU about the progress that is being made. True excellence in research and teaching is a great challenge and there is an urgency that pervades everyone's work.

\section{Teri Pipe, Dean, College of Nursing and Health Innovation}

Dean Pipe joined ASU from the Mayo Clinic because she was "inspired by Michael Crow's vision for what ASU can achieve by defining ourselves based on who we include rather than who we exclude." In leading the College of Nursing, Dean Pipe takes the perspective of a CEO, focusing very much on the potential demand for the services the college can provide and then working to meet them, as opposed to a traditional dean's approach which is more supply-side focused on what the faculty can provide. For example, there is a very large marketplace in the U.S. for increasing the education and credentials of nurses. Research has shown that nurses with a bachelor's degree provide better care than those who do not. Sixty-five percent of the nurses in the U.S. have only an associate's degree, and therein lies great opportunity for the college.

There are approximately 1,600 students in the college and about 700 of these students are in the online-only RN to BSN program. Students in their last year of an associates program can be dually enrolled in ASU's RN to BSN program. The college also has a faceto-face post-bac program to provide a BS in nursing for students with a BA in another program. There are 180 freshmen in the traditional BSN program. 
The nursing program has become very high demand and competitive. Online learning has offered a way to reach more students, both those who are interested and able to pursue nursing degrees and those who may not be at that level of aptitude but want to be in a health-related profession. Admission to nursing programs has become competitive, driven by a national nursing faculty shortage and a dearth of clinical placements. The college is now creating non-nursing majors for students who cannot get into the nursing school. These include bachelor's programs in integrated health (entirely online), health advocacy and education, and clinical research management. The college has also created an online Master's program in healthcare innovation.

The program directors and co-directors have driven the success of the online program and they have been nurse educators for decades. They are always thinking of new markets and how the programs can impact the community. The RN to BSN and DNP are bringing in money that helps support research and the undergraduate program. There has been strong buy-in from faculty from the beginning and the success has made people excited. To design courses, content experts are paired with an instructional designer, which has been very helpful. Although ASU Online supports instructional design, the commitment to online programs is significant enough that the college has hired its own full-time instructional designers. In fact, the college hired away a few ASU Online people to support the college, and will continue to hire more in-house people because the programs are growing. The college uses the eAdvisor services of ASU Online but also supplements those services with additional advising staff. ASU Online takes sole responsibility for marketing the college's online programs.

To decide where to invest the college's resources and focus its programs, Dean Pipe evaluates the gaps between the skills that employers need and what ASU programs provide and she works to fill those gaps and meet the demand. She also attempts to match the strengths of her faculty and their expertise with some potential new programs and attempts to manage risk. She is willing to take some financial risks if she believes there could be a big upside. They are beginning to work with a local hospital system to help their nurses earn a BSN.

When Dean Pipe arrived there was a distinction between undergraduate instructors and tenure-track researchers. Research is valuable for its own sake but it also plays an important role in the educational life of the college. It serves to make people better scientists and nurses so they can better serve the community. Nevertheless, she is encouraging more tenure-track faculty to teach undergrads because "We are in the business of teaching." A lot of new tenure-track faculty are learning to teach online, which means students are engaging with tenure-track faculty in the online courses. She is also trying to get faculty to identify more with the college than with their professional track. 
The college's accreditor requires it to track some metrics of student outcomes such as graduation and retention rates, and it tracks others on its own. Graduates of the college have a 92\% pass rate for state boards and good employment data. One-hundred percent of Native American graduates have passed their state board exam. The retention rate in traditional nursing is over $90 \%$. Recently, there was a dip in retention for the RN to BSN program and administrators immediately worked to try to understand the reasons for that and to take corrective action. The college also interviews its graduates and the reviews have been extremely positive. Dean Pipe has been particularly pleased by positive reactions from people in the online degree program who thought they would hate online learning and from those who could never have pursued a face-to-face BSN due to personal circumstances or family obligations.

Dean Pipe emphasized that things are very entrepreneurial at ASU and everything moves at a faster pace. If she wants to start a new initiative or program she does have to go through channels but can start them much faster than she would be able to at another institution. For example, one program took just a year and a half to go from concept to implementation.

Michael Crow's vision is well understood now by everyone on campus. Part of that vision supports interdisciplinary work. President Crow makes it clear that it is important to overcome silos-each college should be integrated. The deans that are in place or have been hired embrace that vision and are therefore excited to work with each other in novel ways. Getting over the territorial turf issues is key to success. The disciplines face very similar challenges. President Crow is provocative and he makes changes, so naturally faculty opinion of him does vary. But most of the faculty at this point have adapted to his views, in part because of the successes ASU is experiencing. Where there have been negative commentaries on ASU, President Crow has been good at using those to motivate further improvement. In her estimation, President Crow has done a good job of motivating a leadership team comprised of very different people to work together to move the university in a direction consistent with his vision. Part of that vision is to be innovative. Innovation and entrepreneurship is a large part of the ASU vision and because of the numbers they want to reach in terms of students and graduates, they need to use online learning.

The college's strategic plan is intertwined with the university vision, not a formal or detailed ASU strategic plan. The university is changing very quickly so it does not make a lot of sense to follow the classic formal strategic plan. It would likely be out of date before it was completed. It is up to each of the colleges to determine how to meet the broad objectives of the ASU vision. Every college has responsibility to come up with a development, research, innovation, and academic plan so that all colleges are working in tandem and expressing to the administration that they understand what they need to do 
to reach the specific enrollment, research, and retention goals. Of course there are budgets, but there is flexibility so the colleges can take advantage of promising opportunities for hires or new programs, as long as they can develop a funding model to support them. Dean Pipe can relatively easily launch programs with other colleges if she wants. It creates a great collaborative spirit among the deans.

\section{Philip Regier, Executive Vice Provost and Dean, ASU Online}

Dean Regier is the director of ASU Online. He was an accounting professor and then Executive Dean of the business school and was chosen by President Crow to head the ASU online program. At the time that he took it over it was an executive/distance education program more than it was an online education effort. He started with a staff of 30 and a budget of $\$ 3.3$ million. During the first year he had to make major changes, as he did not have the right kind of staff to pursue the agenda he wanted to set for the unit. He reduced the staff deeply, dropping down to 11 by the end of the year. He has since rebuilt the organization and there are now approximately 60 on staff, even though the budget is still less than double the initial amount. His staff includes instructional designers who work with faculty to design courses, as well as staff who provide marketing support to promote enrollment in courses.

When he took over the program, President Crow gave him considerable autonomy to be entrepreneurial in managing and growing the online program. It soon became apparent that there was real opportunity to grow enrollment and help meet the broader needs of the university though online offerings. Dean Regier saw the value in partnering with other enterprises and two key relationships he established early in his tenure were with Knewton, an adaptive learning platform, and Pearson. Together they developed a program in developmental math that has proved to be very successful. Students have done much better in these courses than they used to in the traditional version of developmental math.

The broader marketplace and the preferences of individual deans have driven the various colleges' involvement with ASU Online. The degree programs in ASU Online have the greatest markets. Most (if not all) online programs are either currently offered face-toface or were previously offered face-to-face, in part because faculty approval is not needed if there was previously a face-to-face program. There is only one bachelor's program offered entirely online: the bachelor's in liberal studies. It is a program that was designed to accept virtually all transfer credits. 


\section{Keith Crnic, Department Chair for Psychology}

The Psychology department has 50 tenure-track faculty and nine FTE teaching faculty. There are 1,800-2,000 undergraduate majors and 125 active graduate students. The department does not have difficulty attracting students and therefore enrollments and budgets have been relatively stable.

The types of courses- what is being taught-have not changed much in the last five years. The curriculum is fairly set and has worked for a long time, although he does plan to think more going forward about how well the curriculum is meeting their needs and the needs of the students. There has been more change in how courses are taught. The department is using technology to make classes more interactive in various ways, not necessarily all through online courses.

Some faculty are engaging the new technologies willingly and others are being dragged kicking and screaming. More of those who do engage start with hybrid courses (rather than online courses), in part because there is limited classroom space, especially with the growth in enrollments. Younger faculty are more aggressively using technology in the classroom, but no one is really interested in completely abandoning the bricks and mortar teaching tradition.

The department has relied on instructional technology support provided through the College of Liberal Arts and Sciences to help design its hybrid learning courses. Professor Crnic finds that when the faculty do not have that support they most often rely only on lecturing. The lecture is still the predominant mechanism for delivering curriculum in the psychology department. A lot of faculty are older and resistant to change. For the most part it is the tenure-track faculty who are pushing the interest in online courses.

Despite these obstacles and the fact that the department is doing well, there are several motivations for change. First, he knows that teaching with technology is the future; the department wants to engage students better and meet them where they are. Second, university leadership is pushing this kind of innovation and the department wants and needs to be responsive to that. There are university goals the department has to meet and there are also some financial incentives. The administration encourages departments to move successful iCourses to ASU Online. The ASU Online courses generate discretionary funding, which can then be used to build research capabilities or programs to address specific interests.

To define success, Professor Crnic initially emphasized traditional measures such as student ratings for courses, number of credit hours generated, the number of majors, and the amount of research dollars generated. The latter three are important because 
they are tied to budget allocations. He expressed some concern about relying on measures such as credit hours because they create a zero-sum game that pits departments against one another. They also emphasize quantity over quality. The department is in the process of developing better outcome-oriented assessments.

The department also must report graduation rates, time to degree, retention, and quality indicators such as graduate school placements. The psychology department's retention rates have gone up over time. If the department does not meet its marks on these measures, the university does not penalize it, but there is encouragement to look for ways to do better. One recent development is that ASU now requires freshmen to declare their majors when they enter the university. One reason for this is that the administration wants students to have a home so that there is a mechanism to follow and support them.

There is awareness of the vision and direction of the university and that informs how faculty and staff operate. Although it probably cannot be said that the faculty think about the eight design imperatives on a daily basis, everything they do can be tied back to various imperatives. The imperatives are implicit in the way that they do business-in the people they hire, and in the service and work they do. They are guiding principles for what the faculty do and how they operate.

Professor Crnic emphasized that President Crow's vision of the university is a great mission and appropriate for a public university. No one can argue with those aspirations. He did say candidly that it is a challenge, practically speaking, to reach them. He is proud of the leadership role that several psychology department faculty have had in universitywide initiatives to develop effective retention programs. When you measure retention rates it is obviously easier to succeed if you are a highly selective institution than if you are an inclusive one. There are real challenges associated with successfully teaching and retaining students that are marginally prepared or insufficiently motivated to learn. This is an important challenge for public universities to overcome.

\section{Mari Koerner, Dean, Mary Lou Fulton Teachers College}

[Note: The nature of our conversation with this group of people was different from our other interviews. Instead of responding to a series of questions, Dean Koerner led the group through a conversation about the changes that had taken place at the Mary Lou Fulton Teachers College. Alfredo Artiles, Associate Dean of Academic Affairs, and Barnaby Wasson, CTO, also participated in the conversation.]

Dean Koerner believes that there is strong and clear leadership from the top-anyone can tell you the principle areas of emphasis of the university and everyone at ASU knows 
what Michael Crow's imperatives are. Furthermore, everyone embraces that the institution is going to change and the administration has tried to build processes to engage faculty along the way. There is a mandate for change but also no reprimand for making mistakes.

Eight years ago, before Dean Koerner took the deanship, there were three colleges of education, one on each of the three ASU campuses, each with their own dean and faculty. The college on the Tempe campus was the iconic college. It had approximately 4,000 students and 80 tenured faculty and was ranked 36th in the nation. The perception among many within ASU was that the college was moribund and poorly led. They continued to add PhDs even as undergraduate enrollment was declining. There were 11 elementary education programs throughout the schools. Individual faculty were doing whatever they wanted without controls. It was an unsustainable situation.

Together these factors created a "perfect storm" and it was time for a change. The decision was made to consolidate the various colleges into one. But it was not done gently. Dr. Koerner, who had recently raised nearly $\$ 100$ million in grants, was named Dean, even though she was not at the flagship school/campus. The colleges were not merged; rather, the old colleges were dissolved and a new college created. Faculty were told they could join the new college (and focus on teacher preparation), they could go to another college or department at ASU, or they could leave the university. This was very controversial and created a firestorm of protest both inside and outside the university. Approximately 40 faculty left the university or went to other colleges. There was a lot of misinformation and miscommunication among the faculty and it was unclear what would happen to the college. During this time the college ranking improved from $36^{\text {th }}$ to $24^{\text {th }}$, despite the negative publicity about the changes, because of large increases in external funding.

Dean Koerner was very intentional in focusing on educating undergraduates as the most important role of the college. She set a policy not to hire faculty who are not enthusiastic about teaching undergrads. Before the reorganization, in her opinion, the college admitted too many $\mathrm{PhD}$ and EdD students. Mentoring and course taking patterns were idiosyncratic. The college has since reduced the number of PhD students and is focusing on high quality over quantity by scaling down, being more selective and fully funding the students. The college also established an intensive mentoring approach. The second cohort of the smaller more intense program has just started.

Dean Koerner has exerted strong leadership over the governance and administration of the college. She eliminated two ad hoc committees to reshape the PhD program because they had struggled to make progress due to challenges associated with maintaining disciplinary silos. Now instead of relying heavily on committees, they focus more on 
direct communication between the college administration and faculty. The

administration has also supported change by providing resources that the faculty need for course preparation with IT staff and instructional designers.

The college is using technology in innovative ways to improve the student experience and has attracted grants that support the use of technology in learning. All clinical supervisors have an iPad with which they input results from high stakes performance assessments into a database that is processed and put into a dashboard. The college administration reflects on the supervisors' ratings of students and assessments to determine how to improve student education based on patterns in the data. Dean Koerner believes this is improving the quality of instruction. Faculty have applied techniques from the gaming industry to improve instruction; for example, each undergraduate creates their own avatar and works through simulations in literacy, assessment, professionalism, and more.

These changes, while difficult, are having a positive impact on the college. Faculty who left the college for other departments during the reorganization are coming back, including Dean Artiles, whose return to the college brought enormous credibility because of his reputation and stature. The college is now ranked $18^{\text {th }}$ and is on the rise. The culture has changed to focus on the students and on instruction. Dean Koerner has hired people who want to be a part of this new vision. She rewards faculty with good ideas, and generally tries to expand successes so that they impact the entire college if possible. In general, the change has been extremely successful.

According to Dean Koerner, to be in a leadership position at ASU means you have to be willing to take risks. The president and provost give her enormous autonomy to lead the college, provided it is achieving the goals that have been set out by the basic university principles. Innovation within that framework is encouraged. Leaders build a positive reputation for taking risks and being successful. All of the risk-taking is exciting but it also can make for a rather hectic environment which is not typical of higher education.

\section{Ronald Askin, Director, School of Computing, Information and Decision System Engineering}

Professor Askin has been at ASU for almost nine years. There is very clear direction from the top that is consistent and well-articulated that has enabled ASU to move quickly in a positive way. He has never seen a president who is as "present" in terms of messaging to the faculty as Michael Crow. It is exciting and effective, but also chaotic and stressful.

There are 4,300 students in the School of Computing, Information and Decisions Systems Engineering; there were only 1,580 students just 5 years ago when he took over 
the school. It has grown over 20\% each year for the past few years. 600 of its students are online only.

Because ASU has grown so rapidly there are a lot of people who have arrived since President Crow was hired. There was a consistent approach to hire new people who are comfortable with the ASU vision. People who did not buy in to President Crow's vision have either left or have been overwhelmed by the new people.

The engineering dean is very student-centered and is very focused on undergraduate education. One of the goals is to build social support structures and to create a wellrounded engineering experience. One example of this is an orientation camp offered to incoming freshmen engineering students. Nearly 90\% of freshman take advantage of this 3-day experience in Northern Arizona. The students are introduced to engineering, their peers, the faculty's expectations, and what their experience will be like. This is important because they hear the message that the faculty care. This is a student-run program that they feel has really enhanced the engineering experience.

Technology has been used in teaching for several years. Initially the school just videotaped lectures for master's students and corporate training. Since the advent of ASU Online there has been more work on undergraduate degrees and faculty have been creative with the design to make them better than just video lectures. The school now offers undergraduate degrees online in electrical engineering, engineering management, and software engineering, all of which are fairly new (two began their second year in fall 2014).

There is a small subset of the faculty involved in creating these courses online and they are really the only ones engaged in it. They seemed motivated by the ability to engage students in new ways, but some do it for a stipend or for release time that excuses them from other duties. The school has also hired some lecturers to teach these courses.

As the school started to offer undergraduate degrees online it had to become more systematic in its approach. It had to get other departments to put the necessary courses online in order to have a full engineering degree sequence and curriculum. ASU Online worked with the math and physics departments to facilitate that. The school is developing tutoring services for online students and is also trying to standardize the courses so that they are more comparable to the face-to-face versions. Enrollment in online degrees is growing rapidly-from 100 to 450 for software engineering and up to 150 for engineering management.

Online courses have to be completely scalable and offered without continuing input from the faculty member who created them. Occasionally the faculty creator will update videos 
but otherwise the courses can be completely run by TAs. There is also no cap on enrollment. There is a special online test bank that can be easily graded for the online students, but the content taught is the same. The performance in terms of the grade distribution has been equivalent but the online and face-to-face students perform differently on different kinds of assignments. The online students tend to be more diligent, so they do better on the project assignments. They do less well on standard knowledge-based exams. Online students generally give lower ratings to their courses than students in face-to-face courses.

Professor Askin believes that Michael Crow has driven the development of online courses. The financial incentive for the department has an impact. The money generated by online courses is being used to fund TAs. The school's goal is to use the online money to underwrite PhD students who can then help support faculty research. If online enrollment grows he will use the additional money to hire more faculty and lecturers to teach the courses.

The school does not typically use online technologies to teach immersion students; there are only a couple of iCourses. Those are offered mainly out of necessity because the classes are over-enrolled; they are videos of the traditional versions put online for students to watch.

In the future, Professor Askin expects to build adaptive courses that take fuller advantage of the technologies available. Intelligent tutors are in development and he expects to do more fully virtual education. Professor Askin believes, and the research is starting to show, that it is going to be possible through artificial intelligence and affective computing for intelligent virtual tutors to improve learning in some courses and that in those courses there will be little need for faculty members in the classroom teaching in the traditional way.

Professor Askin believes that an entrepreneurial spirit does exist at ASU, and that there is a willingness to try new things, but like any university there are institutional barriers that need to be overcome, and sometimes they cannot be overcome. There are also challenges arising because of the rapid enrollment growth; it is difficult for the bureaucratic systems to keep up with the increasing numbers of students. For someone in his position, this leads to an enormous number of operational details to track, leaving less time for strategic work. 


\section{Administrators}

\section{Morgan Olsen, Executive Vice President, Treasurer \& Chief Financial Officer}

Dr. Olsen has been at ASU for six years and previously was the CFO at Purdue. He left Purdue for ASU because he was attracted by the vision of ASU as a public university and the challenge associated with delivering high quality education at scale. Last year alone, ASU enrollment grew by approximately 7,00o students, many online only. ASU is leveraging technology to control costs as it increases scale. Technology not only reduces administrative costs but also allows ASU to teach more students for the same costs. Dr. Olsen also believes that adaptive learning technologies are helping ASU to improve the quality of learning in large classes by providing more personalized instruction to address the needs of diverse individuals.

In FY 2013, total revenue was $\$ 1.8$ billion, $\$ 803$ million ( $45 \%$ of total revenues) of which was from net tuition and fees. ${ }^{10}$ The biggest share of revenue used to be state appropriations but these decreased drastically in the period between 2008 and 2012, down $40 \%$ in the aggregate and down $51 \%$ per student when you factor in growth in ASU enrollments over the same time period. State operating and capital appropriations were \$312 million (17\% of total revenues) in FY 2013.

The institution has worked to address the declines in State funding on both the revenue and expense sides of the ledger. Even though ASU has four campuses, it is considered a single university with a single administration. Of course there are challenges but the administration works very hard to integrate the campuses and operate efficiently. In the wake of the financial collapse, ASU eliminated 2,055 FTE positions, mostly in administrative activities. ASU measures and compares its administrative costs against its peers and works to keep these down. The cost of delivering various administrative functions ranges from $35 \%$ to $20 \%$ fewer FTEs than the average for the same function at comparable universities. Using IPEDs data, Dr. Olsen has found that the cost per ASU degree is $25 \%$ less than the average. Expenditures per student have been relatively flat. He has not considered the granular level of costs, such as credit hours, instead focusing more on costs per degree or expenditures per student. He has done some work on measuring the impact on costs of teaching online, but not enough to understand it. Part of the reason is that ASU has been able to grow revenue by adding students online, which takes pressure off reducing the costs of instruction per student.

${ }^{10}$ In FY 2014, total revenue was $\$ 2.0$ billion, with $\$ 897$ billion from net tuition and fees and $\$ 329$ million from state appropriations. See http://www.asu.edu/fs/documents/annual reports/ASU 2014 CAFR.pdf. 
On the revenue side, ASU had to increase tuition aggressively right after the financial crisis, but more recently has grown revenue through increasing enrollments, in addition to modest and targeted tuition increases. In-state tuition has increased but very modestly, averaging $1 \%$ in the last three years ( $0 \%, 3 \%, 0 \%)$.

In addition to these changes in tuition, ASU has made it a priority across the university to increase research funding. Revenue from research grants and contracts was $\$ 425$ million in 2013 (using NSF HERD methodology), up from \$125 million 10 years ago. ASU has set a very aggressive research goal of $\$ 700$ million annually by 2020 .

Notwithstanding the overall trend, there have been increases in state appropriations each of the past three years (4\%, 6\% and 7\% respectively in FY 2013, FY 2014 and FY 2015). The reason for those increases is a change in state policy for distributing appropriations among the three Arizona public universities (University of Arizona (UA), Arizona State University (ASU) and Northern Arizona University (NAU)). In the past, UA received a much larger share of state funding than the other two universities. In 2013, the state determined that there should be "parity" in state investment per student among the three public universities. Since UA historically received a much higher investment per student, parity funding has resulted in additional state appropriations to NAU and ASU over the last three fiscal years, without adjustment to UA. In addition, the state has begun to distribute funding based on performance metrics focused on graduation rates, credit hours completed and research output. This change has had a smaller impact than the shift to parity-based funding, but has also worked in ASU's favor because it has done better than UA and NAU on those metrics. FY 2015 was the last year for the parity-based adjustments so only the performance-based measures will play a role in the allocation of marginal state appropriations in the future.

In order to improve graduation rates and retention, ASU is building systems that allow it to intervene when students are struggling. The university collects data about how students are doing and feeds it into an overall database and dashboard that provides a full view of each student including his or her financial, social, disciplinary, and advising situation. This information enables administrators to target the help students need to stay on track.

One of the most appealing aspects of being at ASU is that the institution embraces change. It is not going to keep doing the same things the same way. ASU makes changes much more quickly than they do at other institutions.

Dr. Olsen worries most about the public loss of trust in higher education. It used to be that higher education was seen as a special kind of institution that was trusted to do what was right for society. Increasingly, universities are regarded as companies, and higher 
education as an industry, with faculty pursuing their own self-interest and expenses that are out of control. Not only do universities need to do a better job of identifying the value proposition of college and balancing the cost, but they need to do a better job of articulating those values to the public.

\section{Arthur Blakemore, Senior Vice Provost, former Chair of Economics}

Until July 2014, Professor Blakemore was the chair of the Economics department. He relinquished that role to focus exclusively on his senior vice provost responsibilities, which are focused on monitoring curriculum redesign initiatives with special emphasis on improving retention and graduation rates.

ASU is starting its redesign efforts with large introductory courses. There has been excellent progress redesigning large introductory courses in chemistry, biology and physics to be delivered online and psychology and economics will be next. In the traditional versions of these courses, retention, success in subsequent classes, and other measures have not been as strong as they need to be. The goal is to improve these outcomes through online delivery. It is planned that pre- and post-testing be put in place to enable evaluation of these outcomes.

There are three objectives for the redesigned courses: 1) improve student success in gateway classes; 2) improve retention and graduation rates; and 3) redesign courses to provide a better foundation in critical thinking skills, which will benefit students in later classes and beyond.

In 2011, Professor Blakemore (as chair of the economics department) had planned similar course redesign for economics, but progress on that effort has been slower than expected. Economics has created three courses for online delivery that are precursors to the adaptive learning courses the department intends to introduce in the future. No tenure-track faculty in economics has been teaching the online courses so there has not been much resistance; however, during the departmental discussion of the decision to create the three existing online courses, economics faculty were supportive.

Retention rates have improved without changes in the standards. People at ASU are aware that standards cannot be lowered just to increase retention or completion. In some cases standards and quality have increased with these technologies, at higher enrollments. Nevertheless, Professor Blakemore cautions against assuming that these new efforts can reduce costs. Lecturing is a pretty efficient way to teach! Creating online courses is an expensive undertaking and must be paid for. Unfortunately, a flipped classroom still requires breaking into smaller groups for engaged learning, which drives up costs and limits the number of students that each instructor can teach. 
Professor Blakemore pointed out that changes in student advising are a somewhat hidden aspect of the ASU technology enhancements. Retention dashboards enable advisers to see everything that is happening to the students they advise. This allows them to know much earlier when a student is struggling, allowing them to intervene to provide assistance.

\section{Sheila Ainlay, Executive Vice Provost for Planning and Budget}

Dr. Ainlay has been at ASU almost 28 years and her graduate degrees (in psychology) are from ASU. She came to West campus when it was launched and then joined Polytechnic campus when it was launched. She assumed her current position six months after Elizabeth Philips was named provost. She focuses on enrollment, academic planning, and budget development. The data analytics teams report up to her, including the office of institutional analysis, which maintains archival data and does external reporting.

Dr. Ainlay tracks and monitors enrollment across schools and develops projections for incoming students, retention, graduation, and financial aid. She also does analysis related to course programming and how students are progressing. She focuses particularly on key metrics that serve as indicators of progress toward ASU's mission to be a top public research university: retention, graduation rates, degrees awarded (to Arizona residents), number of transfer students from community colleges, and research productivity (total research expenditures). Dr. Ainlay believes that Professor Phillips' background in improving student success was one reason she was hired as provost. Retention and graduation rate improvements have served as the metrics for tracking student success. That has been inculcated in the culture of much of the university and there have been significant improvements in retention and graduation rates in the last few years. Research productivity has gone up three-fold during President Crow's tenure, exceeding \$400 million last year. All of these metrics have been identified by President Crow and the board of regents as important for ASU to meet its public university mission.

The recession of 2008 had a big impact on ASU. Appropriations from the state declined dramatically resulting in the need for big cuts. ASU consolidated and reorganized in an effort to cut administrative costs and not cut into academic programs. This ethos continues to guide the approach to cost management. Technology has been used to gain efficiencies in providing services such as advising, improving effectiveness while lowering costs.

ASU has not yet gotten to the point where it monitors and measures the costs of teaching with enough granularity to be able to assess it; the systems are not currently structured 
in a way to allow it. She believes ASU will address teaching efficiency in the relatively near future.

ASU Online provides instructional design services primarily to departments that are just starting to set up online program offerings. Increasingly, support for online programs is integrated into the work of faculty and staff in the departments so it is difficult to account for the online work separately. The bigger departments and some colleges also have their own online support staff.

In general, university oversight of colleges and departments is done by providing measurable, specific goals and targets. For example, each college has its own goal for research expenditures, which rolls up to the goal for the university. The vice president of the Office of Knowledge Enterprise and Development works with the president and the provost to determine each unit's research goals. Each unit develops its own plans for how it will go about meeting the target. Those plans are submitted to the president and the provost.

Planning associated with achieving other metrics has been an ongoing and iterative process. There is continuous monitoring related to new student enrollment, retention, and graduation. There is analysis on steps that can be taken to improve in these areas.

There was some resistance to the changes introduced by President Crow in the beginning. However, the vision and design principles that he sought to implement are inarguable goals for this public university. There is a lot of momentum now. If a new president came in and tried to change the direction, it would be questioned and resisted. Dr. Ainlay estimated that the vision is probably $80 \%-90 \%$ institutionalized, with the remaining $10 \%-20 \%$ in progress.

There is a good relationship between the faculty senate and the administration and there is acceptance that change and innovation are good and necessary. For example, the faculty senate changed the academic calendar to make it more flexible, in part to respond to the needs of ASU Online. As another example, recently the senate was asked to consider a resolution to eliminate the final exam period and instead set semester start and end dates, with exams being administered within that period. The senate has been asked to deliver a recommendation within a few months and they have taken on that accelerated review and process. The institution is adaptive and flexible and not held back by an over-reliance on traditional processes. 
Mr. Wishon has been at ASU for four years. He was previously CIO at Notre Dame and Georgia Tech. He was recruited by Michael Crow out of retirement to be ASU's CIO. Mr. Kazliek has been at ASU for 36 years. Provost Page appointed Mr. Kazliek Vice Provost for Technology; he previously served a similar role in the College of Liberal Arts and Sciences, where Page was Dean. Mr. Kazliek also oversees the group that provides technology to the institution and offers centralized support for systems like Blackboard.

ASU Online never generated substantial enrollments prior to the appointment of Dean Regier who approached it from a business perspective. Dean Regier and his team put together the relationship with Pearson and built ASU Online's enrollment and presence. The relationship with Pearson was a key element because it placed the obligation for student recruiting and support on Pearson. Student enrollment grew from 3-4,00o to 11,000 in a few years.

In the early days the ASU online sphere was separate from online education for residential students-in culture, philosophy and technology. ASU online and iCourses existed as separate entities, and this separation created challenges for students, faculty, and IT support. Many felt that the two types of courses should be more tightly integrated, especially as more faculty began to use online technologies. ASU is now working on that integration, with close collaboration between IT and ASU Online.

The former provost, Betty Phillips, and President Crow played an important role in promoting ASU Online (and online learning more generally) as a way to advance the institution and increase access. ASU Online and the institution generally grew simultaneously in terms of size and student success. This success is largely due to the work of deans and the provost to improve early warning systems and advising systemsusing data in a more targeted way. Research on the elements that contributed to student success enabled the development of systems to predict when students would begin to struggle and implement intervention programs to help students get back on course. Eadvisor is an aggregation of about 30 different applications and programs which lever search technologies, analytics and dashboards and ultimately deliver a more complete picture of an individual student and his/her progress through an individual degree program. It provides leadership with the evidence to guide action.

For Mr. Wishon, the biggest difference between ASU and other places he has worked is the ability at ASU to act upon what the data reveal. The driver for that is leadership from the president and the provost. The cooperation and support of the deans and most of the 
faculty is also important. The secret to success is demonstrating success through evidence in objective measures.

Mr. Wishon came out of retirement to take his job at ASU because he was impressed by the vision for the institution and its commitment to take advantage of technology to meet mission-related goals. Among the people he spoke with he observed an almost universal appreciation for the fact that the only way to provide a high-quality educational experience at this scale (80,000 students and growing) is by effectively leveraging technology. In his view, technology is the only way to personalize the experience for the individual student at larger scale. The leadership's appreciation of technology and support for investments in technology creates a perfect environment for a CIO.

Performance measures are objectives defined in the strategic plan. Mr. Wishon and Mr. Kazliek derived an IT strategic plan from the president's strategic plan. Mr. Wishon reports to the CFO and the provost. There is a constant dialogue with the CFO and the provost about project priorities related to objectives in the strategic plan. Most of the innovation agenda is focused on a set of projects collaboratively developed with the CFO and provost.

Mr. Wishon said that there is a tremendous amount of respect for ASU in the IT world. Where there is skepticism among faculty at other institutions, he believes it derives from a stubborn belief that quality has to suffer as an institution grows its enrollment: "You can't deliver great education and be that big! Faculty won't have time to spend with individual students." Some faculty doubt that technology can be used to provide a highquality, personalized experience to a large number of students.

Mr. Wishon and Mr. Kazliek believe that ASU can provide a high-quality, personalized experience, and is doing so, by leveraging technology. They also believe that the culture has changed ASU to embrace collaboration and innovation. "If you can't do it at ASU, you can't do it anywhere." 


\section{Appendices}

\section{Appendix A}

Eight design aspirations guide ASU's ongoing evolution as a New American University. ASU integrates these institutional objectives in innovative ways to demonstrate excellence, access, and impact.

Leverage Our Place

ASU embraces its cultural, socioeconomic and physical setting.

Transform Society

ASU catalyzes social change by being connected to social needs.

Value Entrepreneurship

ASU uses its knowledge and encourages innovation.

Conduct Use-Inspired Research

ASU research has purpose and impact.

Enable Student Success

ASU is committed to the success of each unique student.

Fuse Intellectual Disciplines

ASU creates knowledge by transcending academic disciplines.

\section{Be Socially Embedded}

ASU connects with communities through mutually beneficial partnerships.

Engage Globally

ASU engages with people and issues locally, nationally, and internationally. 


\section{Appendix B}

eAdvisor ${ }^{11}$

eAdvisor is an electronic advising program intended to improve student retention and success by helping students choose a major, creating a path for students to complete their degree and warning students and their advisors when they are off track. It was developed by Elizabeth Phillips at University of Florida in the late 1990s (where it was called Tracking) and she brought it to ASU when she arrived as University Provost. It was implemented in fall 2008 and is used in conjunction with on-campus advisors.

All full-time freshmen at ASU are required to choose a major when they enter the university. They each have an eAdvisor account and can use it to search majors based on their interests or key words. eAdvisor displays the path to degree for each major, which includes the required courses, timeline of these courses, GPA requirements and major milestones. It also predicts a student's success in a major based on his or her individual characteristics and the success patterns of other students in the program with similar characteristics. The system allows students to directly compare multiple majors. In addition, it enables transfer students or students switching majors to see which credits will transfer to which majors. One goal of this feature is to prevent students from investing time and resources in a major and then switching late in the program because they are unable to meet some requirements. By choosing a major and path early in one's experience, students should be better prepared to excel in a major that is a good fit.

Once a student has selected a major, eAdvisor identifies when a student needs to take courses and monitors a student's course registration. It front loads key courses so that students must pass the critical courses before getting too far into their major. It also requires that students take courses that match their chosen major. This process enables departments to ensure that enough seats are available in the critical classes because eAdvisor predicts how many students will need to take which courses in the upcoming semester and departments adjust their course offerings accordingly.

eAdvisor displays a personal major map for each student and shows when courses are taken and the grades received. Student data is continually updated and progress reports

${ }^{11}$ This summary is compiled from the following sources:

http://www.changemag.org/Archives/Back\%20Issues/2013/January-February\%202013/improving-advising-full.html; http://www.nytimes.com/2012/07/22/education/edlife/colleges-awakening-to-the-opportunities-of-datamining.html?pagewanted=all\& $\mathrm{r}=0$; $\underline{\mathrm{http}}$ ://hechingerreport.org/content/student-advising-plays-key-role-in-collegesuccess-just-as-its-being-cut 10109/; https://eadvisor.asu.edu/. 
are issued so it is easy to determine when a student is off track. eAdvisor emails the student and the advisor and displays a message on MyASU when a student is off track. The advisor will set up a meeting with the student to address the concern and the student will be unable to register for courses until the advisor has removed the hold. In addition, departments identify courses critical for success in a major and eAdvisor flags students in these courses who may need additional academic support. It also offers advice on choosing a different academic program when students are struggling in critical courses.

eAdvisor consolidates information from other sources around ASU, including financial aid, residence halls and campus police. This provides a more complete picture for advisors so that they can provide strong support for students. All students are required to meet face-to-face with advisors in addition to using the eAdvisor system. 